\title{
Les mises en prose, Études réunies par Aimé Petit
}

\section{Maria Colombo Timelli}

\section{(2) OpenEdition}

\section{Journals}

\section{Édition électronique}

URL : http://journals.openedition.org/studifrancesi/9799

DOI : 10.4000/studifrancesi.9799

ISSN : 2427-5856

\section{Éditeur}

Rosenberg \& Sellier

\section{Édition imprimée}

Date de publication : 1 octobre 2007

Pagination : 420-421

ISSN : 0039-2944

\section{Référence électronique}

Maria Colombo Timelli, «Les mises en prose, Études réunies par Aimé Petit », Studi Francesi [En ligne], 152 (LI | II) | 2007, mis en ligne le 30 novembre 2015, consulté le 09 janvier 2021. URL : http:// journals.openedition.org/studifrancesi/9799; DOI : https://doi.org/10.4000/studifrancesi.9799

Ce document a été généré automatiquement le 9 janvier 2021.

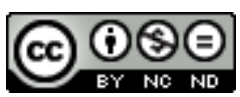

Studi Francesi è distribuita con Licenza Creative Commons Attribuzione - Non commerciale - Non opere derivate 4.0 Internazionale. 


\title{
Les mises en prose, Études réunies par Aimé Petit
}

\author{
Maria Colombo Timelli
}

\section{RÉFÉRENCE}

«Ateliers» 35, 2006. Les mises en prose, Études réunies par Aimé PETIT, pp. 67.

1 Cette dernière issue de la revue lilloise réunit quelques-unes des contributions présentées à une journée d'études organisée en mars 2004 par le Centre d'Études Médiévales et Dialectales de l'Université de Lille 3.

Sarah BAUDELLE-MICHELS, Mise en prose de "Renaut de Montauban": un changement d'univers, pp. 11-20.

3 Les mises en prose de Renaut de Montauban se divisent en deux familles: une compilation cyclique restée sans descendance et une version 'courte' transmise par sept manuscrits et bientôt imprimée (on en connaît de nombreux incunables, puis des éditions lyonnaises et parisiennes du $\mathrm{xvi}^{\mathrm{e}}$ siècle). La comparaison de la chanson en vers du ms. La Vallière avec la version en prose transmise par l'incunable de Lyon (1483-85), en tenant compte éventuellement de l'édition de B. Rigaud (Lyon, 1583), permet à S. B.-M. des observations ponctuelles concernant, d'un côté, le dépouillement du texte déterminé essentiellement par l'abandon du caractère formulaire de l'expression épique, de l'autre côté la redondance de l'adaptation en prose et la nouvelle organisation linéaire et épisodique du récit. Sur un plan plus général, le passage à la nouvelle forme accentue la primauté de la diégèse; surtout, le changement de technique entraîne un changement de registre et de conception du monde: la 'déspiritualisation' dont parle Thomas Pavel.

4 Maria colombo timelli, "La Manequine" en prose de Jean Wauquelin (vers 1450) et les provinces du Nord, pp. 21-29.

5 Sont soulignés ici les liens que la version en prose du roman de Philippe de Rémi tisse à plusieurs niveaux avec le Nord. Le manuscrit unique conservé à Turin est d'abord 
incontestablement lié à la ville de Mons; deuxièmement, le commanditaire et destinataire du texte, Jean de Croÿ, fut un grand fonctionnaire de Philippe le Bon, duc de Bourgogne; l'auteur de la prose, Jean Wauquelin, homme du Nord lui aussi, exerça son activité à Mons entre 1428 et 1452, date de sa mort; encore, la langue du manuscrit turinois - qui n'est cependant pas autographe - apparaît profondément marquée de traits picardisants (phénomènes graphiques, phonétiques, morphologiques, lexicaux). Enfin, la géographie interne du roman se fait extrêmement précise lorsque le récit se déroule dans des régions (la Flandre et la France du Nord) manifestement bien connues tant de Philippe de Rémi que du 'prosateur'.

6 Jean-Charles HERBIN, Yonnet de Metz, pp. 31-45.

7 Le récit consacré à Yonnet de Metz, relié à la Geste des Loherains, nous est parvenu sous une forme versifiée, remaniement du xiv siècle d'un original perdu (ms. N), et dans la version en prose de Philippe de Vigneulles (entre 1515 et 1528; transmise par un ms. autographe, $v$, et une copie ultérieure, $h$, représentant l'ultima vox de l'auteur). J.-Ch. H. examine les corrections successives introduites par Philippe, qui s'expliquent en général par un souci de precision dans le contenu et une certaine attention au rythme de la phrase; surtout, certains commentaires et interventions semblent lui appartenir en propre, ainsi que l'organisation en chapitres (qui ne reflèterait pas le découpage en laisses du modèle) et la création des rubriques. L'intérêt de la prose du xvie siècle réside cependant dans sa valeur 'documentaire', comme l'aurait dit Georges Doutrepont, puisqu'elle permet de reconstruire le fonctionnement du cycle de la Geste tout entière, que le ms. $N$ ne révèle pas entièrement.

Aimé PETIT, La chasse à l'octosyllabe dans la mise en prose du "Roman de la Violette": l'épisode de Marote, pp. 47-53.

9 Les deux manuscrits (Bruxelles, KBR 9631, édité par F.F.H. Lowe en 1928; Paris, BnF fr. 24378) qui ont transmis l'adaptation en prose du Roman de la Violette entretiennent un rapport différent avec la source en vers. C'est ce qui ressort de la lecture comparée de l'épisode où Gérard, tombé malade, reçoit les soins de Marote, la fille du bourgeois qui l'a accueilli. En effet, alors que le ms. $B$ conserve un nombre important d'octosyllabes (une cinquantaine sur un fragment de 234 vers) et en reformule à peine beaucoup d'autres, $P$ s'avère bien plus indépendant. Si ce traitement était confirmé par l'analyse d'une portion plus significative du texte, l'hypothèse d'une première rédaction proche du modèle $(B)$, suivie d'une version plus 'libre' $(P)$ deviendrait très vraisemblable.

Philippe VERELST, "Mabrien": de la prose manuscrite à la prose imprimée, pp. 55-67.

11 Les versions imprimées de Mabrian (la plus ancienne, 1525, est due à Galliot Du Pré et Jacques Nyverd; c'est cependant celle de 1530, du même J. Nyverd, qui est considérée ici) présentent des différences intéressantes par rapport à la version manuscrite, qui, elle, porte le titre de Mabrien. L'analyse proposée par Ph. V., limitée aux chapitres IXVII, met en relief des amplifications considérables par rapport tant à la source en vers (xiv siècle) qu'à la prose du $\mathrm{xv}^{\mathrm{e}}$ siècle: ajout de détails, de précisions, attention accrue pour le cérémonial, le decorum, les rituels sociaux et guerriers, la généalogie, introduits dans le but didactique et édifiant, affirmé en toutes lettres dès le prologue, de faire revivre les vertus pratiquées dans le passé. 